\title{
Augusto e a (re)organização administrativa do Sul da Lusitânia
}

\author{
João Pedro Bernardes \\ Universidade do Algarve \\ jbernar@ualg.pt
}

\section{RESUMO}

Fontes literárias, numismáticas e arqueológicas permitem-nos conhecer vários oppida no sul da Lusitânia no século I a.C. Como noutras partes da Hispânia, a nova ordem administrativa desenhada por Augusto em finais desse século, vai hierarquizar e escolher para capital de civitates vários desses povoados. Nem todos irão ter sucesso; a presença ou ausência de elites, os recursos locais ou o investimento em infraestruturas desde cedo ditarão o sucesso de uns e o definhamento de outros até, por vezes, ao seu desaparecimento. O desenvolvimento do processo da nova ordem iniciada por Augusto acabará por culminar numa nova realidade em que a parte mais visível é o desmantelamento da estrutura tribal e a emergência de um novo território dominado por novas centralidades e redes regionais. Este artigo analisa as mudanças mais significativas operadas no sul da Lusitânia na sequência da reforma augustea.

Palavras chave: Oppida. Lusitânia. Augusto. Reforma Administrativa.

\section{Augustus and the Administrative Reorganization of Southern Lusitania}

\begin{abstract}
Literary, archaeological and numismatic sources allow us to meet various oppida in southern Lusitania in the 1st century BC. As in other parts of Hispania, the new administrative order drawn by Augustus at the end of this century, will rank and choose to capital of civitates several of these cities. Not all will succeed; the presence or absence of elites, the local resources or investment in infrastructure will lead the success of a few and the wasting of other, even sometimes to its disappearance. The development process of the new order initiated by Augustus will culminate in a new reality in which the most visible is the dismantling of the tribal structure and the emergence of a new territory dominated by new centralities and regional networks. This paper observes the most significant changes operated in southern Lusitania.
\end{abstract}

Key Words: Oppida. Lusitania. Augustus. Administrative Reform.

Sumario: 1. Oppida e populi de finais do século I a.C. no sul da Lusitânia. 2. A organização administrativa de Augusto e a criação das civitates.3. A Evolução do legado de Augusto no sul da Lusitânia. 
Augusto sabia que se era difícil conquistar territórios, como foi o caso da Hispânia, era extremamente fácil perdê-los. Concluída a conquista, a melhor forma de manter os novos territórios na esfera de Roma seria pela sua integração total só possível com Pax e progresso, onde todos pudessem participar. A política de tolerância e de não afrontamento na hora de delimitar territórios e centros administrativos foi por isso mesmo respeitadora das realidades etnogeográficas pré-existentes. Para a integração plena era, no entanto, preciso muito mais do que um bom controlo político baseado numa bem organizada rede administrativa, tendo em conta que seriam sobretudo as elites provinciais as dinamizadoras desse processo. Desde logo era necessário construir oportunidades e atrativos socio-económicos abertos a todos, particularmente aos autóctones, que permitiriam reforçar o seu bem estar e respetivos estatutos; depois criar símbolos identitários de uma nação que, tendo Roma como cabeça, respeitaria e integraria muito das realidades locais. A aposta de Augusto fez-se aqui em duas frentes onde os seus homens de confiança como Agrippa e Mecenas tiveram um papel de destaque. O primeiro na criação desse bem-estar, da identidade através da obra e dos símbolos materiais de que a fundação de Mérida ou o financiamento de múltiplas obras públicas provinciais são exemplo; o segundo promovendo símbolos culturais de forte pendor integrador e unificador, de que obras como a Eneida de Vergílio ou a De Architectura de Vitrúvio são esteios tão importantes quanto a imagem do imperador disseminada por todas as cidades e cantos do Império. Esta visão global e integradora de Augusto dos territórios conquistados através de um enorme processo propagandístico, ordenador e "civilizador" acabarão por lançar as bases que justificam o sucesso e a durabilidade desse mesmo Império. E é neste processo vasto e complexo que desde o início do principado se recolhem e sistematizam todo o tipo de informações que permitem desenhar as reformas que se assumem como uma verdadeira revolução, como bem viu R. Syme, cujo alcance é sobretudo o de uma revolução cultural de Roma projectada à escala de todo o Império, onde as manifestações simbólicas e culturais de identidade por parte dos cidadãos são, na sua diversidade, cada vez mais importantes. ${ }^{1}$

É claro que a organização administrativa de qualquer território, como o da Lusitânia, com o intuito de o integrar numa unidade política e cultural é sempre um processo lento e de longa duração, ainda que as intenções e decisões sejam bem efetivas e determinadas no tempo. O ponto de partida para Roma é a escolha de lugares ou povoados centrais já existentes como centros administrativos dos territórios, cujos limites respeitam, quase sempre e quando possível, as divisões e identidades etnogeográficas autóctones. As fontes, sobretudo literárias e numismáticas, dão-nos a conhecer o nome de vários oppida do sul da Lusitânia que constituíam esses lugares centrais em pleno século I a.C., e que vão ser tidos em conta pela reforma administrativa de Augusto, levada a cabo em finais desse século.

1 Wallace-Hadrill 2008, 453. 


\section{Oppida e populi de finais do século I a.C. no sul da Lusitânia}

As referências da lista pliniana, baseada em fontes da época de Augusto, reflectem um alargado conjunto de lugares centrais pré-romanos, hierarquizando-os já de acordo com critérios e estatutos atribuídos pela política administrativa romana. A fonte principal em que se baseia Plínio é o chamado mapa de Agrippa, que compila informações até 12 a.C. que descrevem o orbis terrarum. Este mapa de que Plínio (III 17) nos dá conta e se localizava no porticus Vipsania no Campus Martius, terá sido acabado entre 7 e 2 a.C., após a morte prematura de Agrippa, em 12 a.C. Reúne fundamentalmente informações político administrativas anteriores àquela data, pelo que a lista de Plínio dá conta da realidade Hispânica centrada na penúltima década do século I a.C. Por aí ficamos a conhecer as cidades do litoral atlântico a sul do Tejo, as colónias ou os povoados centrais de menor estatuto, sujeitos ao pagamento de um stipendium, e que corresponderão a capitais de civitas já definidas pela reforma administrativa de Augusto, fundamentalmente através das seguintes passagens:

Para lá do Tejo, as mais notáveis cidades da costa são Olisipo, célebre pelas éguas que concebem do Favónio, Salácia, cognominada Urbs Imperatoria, Meróbriga e, entre os promontórios Sacro e Cúneo, os ópidos de Ossonoba, Balsa e Mirtilis (Plinio, IV 116)

As colónias são: Augusta Emerita, situada junto ao rio Anas; a de Metellinum, a de Pax lulia (...) os ópidos de direito latino antigo são Ebora, também chamada Liberalitas lulia, Mirtilis e Salacia (Plinio, IV 117)

De entre os ópidos estipendiários, sem custo se podem citar, para além dos que já referimos quando tratámos dos cognomes das cidades da Bética, os seguintes: (...) Aranditani, Arabricenses, Balsenses, (...) Cilibitani (...) Mirobricenses cognominados Célticos (...) (Plinio, IV 118)

Havia outros povoados pré-romanos importantes, desempenhando de alguma forma papéis de centralidade mas que, talvez por não fazerem parte da rede de lugares centrais da nova ordem administrativa romana não são referidos como oppida na lista pliniana. Ipses e Baesuris serão dois destes povoados que são conhecidos por emissões monetárias, provavelmente de meados do séc. I a.C. ${ }^{2}$ Ipses tal como o oppidum dos Cilibitani de Plínio, é ainda referido pelo denominado Papiro de Artemidoro sob a grafia de Ipsa e Kilipe, respectivamente. ${ }^{3}$ Baesuris aparece referido em itinerários viários como caput viae, quer no Itinerarium Antonini $(425.6$; 431.4) quer ainda na mais tardia cosmografia compilada por um clérigo anónimo de Ravena (Ravennatis Anonymi Cosmographia, 306.9). Um terceiro povoado omitido por Plínio é Lacco-

2 FARIA 1997, 363-365; DCPH II, 76.

3 GALlazZI - KRAMER - SETTis 2008. A localização destes oppida na costa portuguesa nas atuais localidades de Silves/Lagos (?) e Vila Velha de Alvor e a consequente identificação com Cilpes ou Ipses bem conhecidos pelas emissões monetárias, não é consensual. Sobre o tema e entre o muito que já se tem escrito veja-se, Kramer 2006, Ruiz Acevedo - Campos Carrasco 2009 e Alarcão 2010. 
briga, frequentemente associado a um episódio das guerras sertorianas descrito por Plutarco (Sert., 13) e apontado por P. Mela (III 1.7) como um dos oppida do ocidente algarvio e que tem hoje sido identificado com as ruínas de Monte Molião, em Lagos. ${ }^{4}$ Recentemente foi proposta a foz do rio Arade, na área da actual cidade de Portimão, como a localização da $M a$ [inoba] do papiro atribuído a Artemidoro que a situa a 24 estádios de Ipsa e que corresponderia à Maenoba que Estrabão (III 2.5) refere a ocidente de Ossonoba. ${ }^{5}$

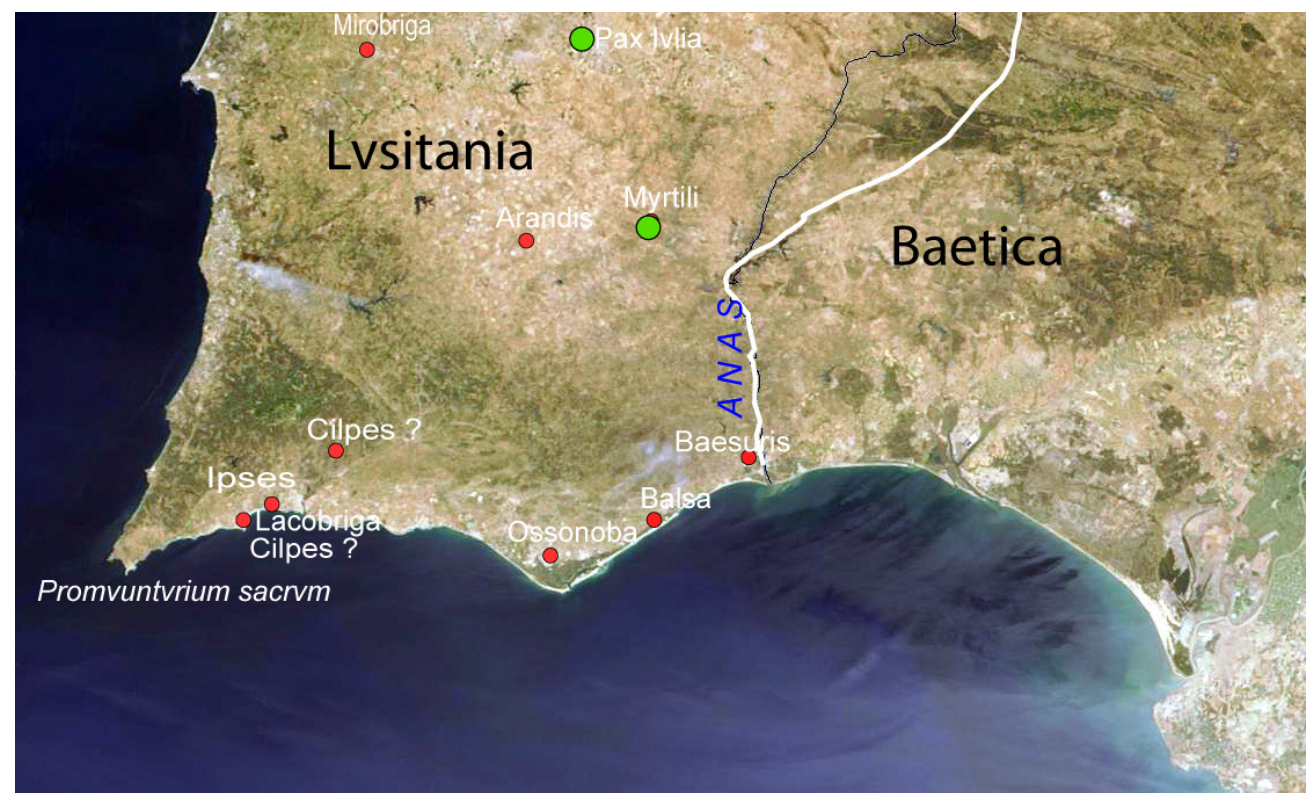

Fig. 1. Os oppida da sul da Lusitânia no século I a.C. conhecidos pelas fontes literárias e numismáticas.

A sul do paralelo de Olisipo, Ebora e Emerita, as cidades lusitanas privilegiadas da lista de Plínio são a colónia Pax Iulia e a cidade de direito latino antigo Mirtilis. Muito se tem discutido sobre quando estas duas cidades terão recebido estes estatutos de privilégio que têm vindo a ser atribuídos mais ao consulado de Augusto do que ao de César, ainda que a data dessa atribuição está longe de ser consensual.

Sabe-se hoje, ao contrário de há alguns anos atrás, que Pax Iulia não é uma fundação ex nihilo, assentando sobre um importante povoado pré-romano que escavações recentes têm vindo a revelar. Estes novos dados tornam desde logo obsoleta muita da argumentação sobre a data da fundação e atribuição do estatuto à cidade, inclinandose hoje a investigação a que essa atribuição seja de Augusto, ainda que, por falta de dados inequívocos, não existe concordância se foi durante o período de Octaviano

4 ArRuda ET AL. 2008.

5 Alarcão 2010, 117. 
ou se em pleno imperialato. A. Marques Faria, por exemplo, baseado em emissões monetárias e no nome da cidade, tem insistido que a fundação da colónia terá ocorrido entre 31 a.C. e 27 a.C. no quadro das várias deductiones de Octaviano a seguir à vitória de Actium. ${ }^{6}$ A amoedação com os símbolos da paz pretendia, tal como a palavra Pax do nome da cidade, comemorar e promover a nova era de pacificação que se iniciava com a derrota de Marco António e a remoção de toda a ameaça à afirmação da estratégia posta em marcha anos antes. Outros autores como Vasco Mantas ou Conceição Lopes argumentam a favor de que a fundação do estatuto colonial deverá antes ter ocorrido aquando da segunda viagem de Augusto à Hispania no quadro da reorganização das províncias mais ocidentais, o que parece estar mais de acordo com os dados arqueológicos que nos últimos anos têm vindo a público. ${ }^{7}$

Ainda que alguns autores considerem que o estatuto de ius veteris latii tenha sido atribuído a Mirtilis (ou Murtilis) por César, foi certamente Augusto a fazê-lo antes de 12 a.C., tendo em conta a fonte pliniana que, neste ponto, se inspira sobretudo nos dados geográficos de Agrippa, e após 27 a.C. Este estatuto deve ser visto como parte da estratégia de Augusto de organizar a paz e o progresso da sua província da Lusitânia, que tendo Emerita como nódulo não podia prescindir de outras cidades que auxiliariam a capital da província na tarefa de ordenar todo o território. É assim que Estrabão (III 2.15) e Dio Cassius (LIV 25.1) referem com as colónias recentes outros povoados, onde certamente e integraria Mirtilis, que beneficiaram de liberdades e privilégios, e que já estariam bem integrados no modo de vida romano contribuindo para o esforço integrador e ordenador da pax. Os testemunhos arqueológicos de Mirtilis são claros quanto à importância que a cidade atingiu durante o século I a.C., ${ }^{8}$ permitindo supor que constituía um ponto estratégico no controlo do território, porquanto era um porto que ligava toda a mesopotâmia entre o Guadiana e o Tejo ao Mediterrâneo. Aliás, neste quadro, Iulia Mirtilis, conforme a designa Ptolomeu (2.5.5), tem que ser compreendida em conjunto com Pax Iulia uma vez que funcionava como o seu porto e ambas as cidades devem ser encaradas como fundamentais ao abastecimento de Mérida e ao controlo e desenvolvimento de toda a região durante a época augustea.

A civitas mais ocidental do Algarve tem sido identificada frequentemente com Laccobriga ou Cilpes. ${ }^{9}$ Ao contrário de Balsa e Ossonoba - arqueológica e epigraficamente bem identificadas em Luz de Tavira e Faro, respetivamente - o facto de não existir semelhante evidência na parte oriental do Algarve tem levado à discussão sobre a localização dessa civitas. Mesmo as recentes escavações de Ana Margarida Arruda em Monte Molião (Lagos), onde tradicionalmente se tem localizado a Laccobriga de Mela (III 1.7), não permitiu resolver inequivocamente o assunto, uma vez que continuam a faltar dados epigráficos e os elementos arquitectónicos de cariz itálico equivalentes aos dos centros urbanos do sul da Hispânia. As escavações permitiram, porém, comprovar que aquele núcleo foi muito mais importante na parte final da época republicana do que no período imperial, durante o qual vai decaindo até

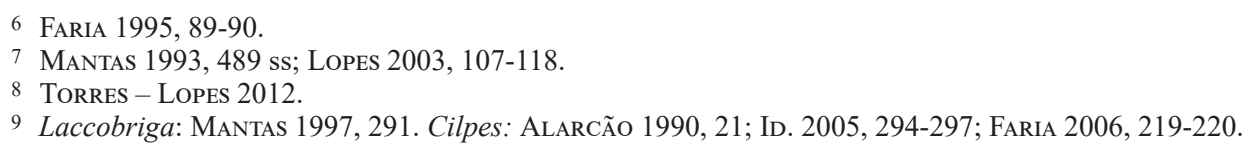


praticamente se despovoar, a partir de finais do século II, em virtude da população se ter deslocado para a outra margem do estuário da ribeira de Bensafrim, onde se assiste a um grande desenvolvimento de unidades industriais de preparados piscícolas. ${ }^{10}$ O núcleo poderá mesmo ter tido um papel de centralidade durante o período republicano, tendo em conta que essas funções foram numa primeira fase frequentemente exercidas a partir dos núcleos nativos, como facilmente se comprova por aqueles que cunharam moeda ou outros que, não o fazendo, desempenhavam papel central no controlo do território. ${ }^{11}$

Cilpes tem sido identificado com o Cerro da Rocha Branca, povoado cerca da cidade de Silves, ou mesmo com esta cidade. Porém, vestígios romanos que apontem para a existência de qualquer núcleo urbano, mesmo que pequeno, estão praticamente ausentes de Silves ou suas imediações. O Cerro da Rocha Branca poderá, quando muito, corresponder a um oppidum da Idade do Ferro com continuidade durante o período romano até ao seu abandono, à semelhança de outros no Algarve. ${ }^{12}$ Foi recentemente sugerido que Cilibis, cidade dos Cilibitani de Plínio e que Artemidoro chama Kilibe e localiza na foz de um rio, talvez correspondesse ao Monte Molião, ficando Laccobriga situada noutra área, eventualmente fora do Algarve, como as coordenadas dadas por Ptolomeu sugerem. ${ }^{13}$ São vários os argumentos para situar Laccobriga fora do Algarve, admitindo que Mela é o único que indica a sua localização no extremo sul de Portugal, eventualmente por erro. Muitos autores preferem ante situá-la na área de Setúbal para onde apontam as coordenadas que Ptolomeu lhe dá ou ainda a cerca de 20 quilómetros a sul de Gaia onde o Itinerário de Antonino (421.7) situa uma Langobriga (veja-se por exemplo. ${ }^{14}$ A grafia do povoado referida por Mela parece ajustar-se mais a Laccobriga do que a Langobriga ${ }^{15}$ excluindo a cidade referida pelo Itinerário, o que não resolve o problema de localização, até porque era frequente existirem na época romana vários povoados com o mesmo nome. Não deixa de ser estranho que só Mela se refira a Laccobriga, no Algarve, pois sendo um povoado importante ao ponto de ser sitiado por Metelo e socorrido por Sertório, conforme nos conta Plutarco (sert. 13), era com certeza povoado de referência na primeira metade do século I a.C. passível, portanto, de ser indicado por outras fontes da época ou posteriores.

Artemidoro posiciona Kilibe a ocidente de Ipsa, sensivelmente à mesma distância que separa Alvor velho, correntemente identificado com este último povoado, do Monte Molião. Na verdade as várias hipóteses de localização quer de Laccobriga quer de Cilpes/Cilibis/Kilibe serão um problema insolúvel enquanto não surgirem novos dados, nomeadamente epigráficos. O mesmo se poderá dizer sobre se Ma[enoba] ficava ou não na foz do rio Arade e se Ipsa corresponde efetivamente a Alvor.

10 Arruda et AL. 2008, 40-42.

11 KEAY 2003, 157.

12 ARRUDA 2002, 53-56; 2005.

13 Alarcão 2010, 115.

14 Spann 1981, 234.

15 Alarcão 2010. 
Já para o Algarve central e oriental as dúvidas não são tantas. Conhecem-se bem as localizações dos três povoados principais pré-romanos atestados pelas fontes literárias, numismáticas e arqueológicas. O povoado de Baesuri, que se identifica com a colina do castelo de Castro Marim, tem sido escavado por Ana M. Arruda, ${ }^{16}$ comprovando-se uma ocupação que remonta à Idade do Bronze. Teve um desenvolvimento assinalável durante a época republicana na tradição da Idade do Ferro e, à semelhança do Monte Molião, o período imperial é de estagnação ou mesmo de regressão até ao abandono no século II, altura em que se observa um abandono progressivo da colina, ao mesmo tempo que se verifica uma disseminação de vestígios em seu torno. $\mathrm{Cu}$ nhou moeda durante a República, ${ }^{17}$ foi porto e importante estação viária, pelo que é referida em itinerários viários como o Antonini Itinerarium $(425.6 ; 431.4)$ ou no do geógrafo conhecido como Anónimo de Ravenna (306.9) que se baseia naquele. Para além destes itineraria ou do numisma ali cunhado com a legenda BAESURI não há quaisquer outras fontes que se lhe refiram.

Ao contrário, Balsa e Ossonoba estão bem representadas nas fontes literárias e epigráficas, correspondendo às enormes áreas de ruínas que se encontram nos subsolos de Luz de Tavira e da actual cidade de Faro. Correspondiam às duas grandes cidades que se desenvolvem no extremo sul de Portugal durante o período imperial de acordo com modelos itálicos. As origens pré-romanas de Balsa estão pouco esclarecidas, e vários são os autores a proporem uma transferência do núcleo primitivo da actual cidade de Tavira, onde existem níveis pré-romanos bem documentados, para a área de Luz de Tavira. O núcleo genético de Ossonoba está bem documentado na colina amuralhada da capital algarvia, com níveis que remontam pelo menos ao século IV a.C. Os dois povoados pré-romanos, beneficiando do clima de pax e da sua centralidade, vão atingir a partir de Augusto um notável crescimento, transformando-se nas duas cidades mais importantes da parte meridional do conventus pacensis. Ambas terão cunhado moeda em período do final da República e são as mais evocadas nas fontes literárias que se referem ao extremo sul da Lusitânia. ${ }^{18}$

Um pouco mais a norte, já fora do Algarve, Miróbriga, referida por Plínio como cidade celta e com uma importante área arqueológica localizada junto a Santiago de Cacém, constitui outro povoado pré-romano que teve um desenvolvimento assinalável no período imperial, sobretudo no século I e II e com uma ocupação que se estende até ao V. ${ }^{19}$ A par do Mirobricenses qui Celtici cognominantur, Plínio (IV 118) refere os Aranditani, outro oppidum stipendiarium cuja localização é mais complexa. O povoado central dos Aranditani, denominado Arandis (Ptolomeu, II 5.5) ou Aranni de acordo com o Itinerário de Antonino (426.3) ou o do Anónimo de Ravena (306.13), situava-se, segundo o primeiro daqueles itinerários, a 60 milhas para norte de Ossonoba. Constituiria assim uma estação viária intermédia entre a cidade algarvia e Pax Iulia que se situaria, transposta a serra, já no Alentejo. Mas onde? A área de Garvão/ Ourique tem sido, desde os anos 60, uma das possíveis localizações apon-

16 ARruda 2002, 36-53.

17 Faria 1997, 361-362; García-Bellido - Blázquez 2001, 50.

18 Bernardes 2010.

19 Quaresma 2012, 305-306. 
tadas; outra, Santa Bárbara dos Padrões, de acordo com a distância que separa esta atual localidade alentejana da cidade de Faro, onde ficava Ossonoba, e ainda tendo em conta que em Santa Bárbara existe uma notável área arqueológica. ${ }^{20}$ De qualquer forma Arandis ficaria no Baixo Alentejo, a sul de Pax Iulia e a ocidente de Mirtilis, sendo os territoria da suas civitates confinantes.

Para além dos populi conhecidos através das fontes literárias, numismáticas ou epigráficas, existiriam muitos outros povoados no século I a.C., mais ou menos importantes, espalhados pelo território, e que nos são revelados pela arqueologia de campo, nomeadamente por escavações. Mesas do Castelinhos, a 9 quilómetros a Oeste de Almodôvar, é um desses povoados relativamente bem conhecidos pelo já vasto conjunto de campanhas de escavações arqueológicas ali desenvolvidas. ${ }^{21}$ Com uma ocupação que remonta ao século IV a.C. e um certo dinamismo coincidente com a chegada dos Romanos nos século II e I a.C., começa a decair a partir do principado de Augusto até ao abandono total nos finais do século I ou inícios do seguinte. A sua articulação económica com as regiões mais a sul e oriental durante os finais da República está bem documentada, nomeadamente através da presença de moedas dos portos de Mirtilis e sobretudo de Ossonoba que demonstram que Mesas do Castelinho se inseria perfeitamente nas redes comerciais do sul da Lusitânia. A alteração dos eixos da vida económica para outras paragens, eventualmente com as rotas de circulação sul/ norte a afastarem-se do povoado, terá sido determinante para a decadência paulatina no período imperial a favor de outros centros mais dinâmicos e importantes, como Ossonoba, Mirtilis ou Pax Iulia.

Nas proximidades de Tavira, o povoado do Cerro do Cavaco, nunca escavado mas com um conjunto de materiais de superfície muito coerente que configura uma ocupação romana circunscrita ao período da conquista, é também abandonado em meados do século I a.C., data a partir da qual se conhecem dados consistentes em Luz de Tavira, onde se desenvolveu a cidade de Balsa. Se o primeiro destes povoados parece ter sido claramente excluído do plano traçado pela nova ordem administrativa de Augusto, já o segundo, de que não se conhecem vestígios pré-romanos, parece corresponder a uma ocupação temporária e de circunstância, que poderá ter acabado quando se escolhe a colina da actual quinta de Torre d'Aires, em Luz de Tavira, como sede da civitas Balsensis. De qualquer forma, ambos os sítios manifestam claramente evoluções ocupacionais determinadas pela nova ordem administrativa do tempo de Augusto, demonstrando que a escolha de lugares centrais como sede das unidades territoriais definidas como civitates levará, a prazo, à queda paulatina de alguns povoados a favor do desenvolvimento de outros.

\section{A organização administrativa de Augusto e a criação das civitates}

O testemunho de Dio Cassius (LIV 23.7) de que Augusto durante a sua segunda estada na Gália e na Península criou colónias - o que é sancionado pelos próprios es-

20 BERNARDES 2006.

21 FABIÃo - GUERRA 2010. 
critos do Imperador (Res Gestae 28) e que Estrabão (III 2.15) especifica enumerando as colónias de criação recente de Emerita Augusta, Pax Augusta e Caesaraugusta abona a favor de que efetivamente a criação da colónia se tenha processado entre 15 e 13 a.C. Sabemos por Dio Cassius (LIV 19.1) que em 16 a.C. Augusto parte para a Gália. Sabemos ainda pelo Edito de Bierzo, também conhecido como Tessera de Paemeiobrigensis, ${ }^{22}$ que em 14 ou 15 de Fevereiro do ano seguinte se encontrava em Narbona, onde provavelmente terá passado o Inverno, partindo então para a Hispânia. Aquele Édito alude ainda a uma província transduriana, denotando que no início do ano 15 a.C. ainda não se efectivara o reordenamento administrativo das Hispânias que acaba com aquela província e fixa os limites da Lusitânia no Douro. Serão também por esta altura criadas as civitates e no quadro da hierarquia administrativa e das deductiones de militares após o fim das sublevações militares em 16 a.C., as colónias enumeradas por Estrabão. Seguindo a velha tradição romana de uma Hispânia bipartida, a criação de Caesaraugusta e de Pax Iulia pretendiam, na concepção augustana, auxiliar nas tarefas politico-administrativas as duas capitais das províncias imperiais: Tarraco e Emerita Augusta. Ainda que não proponhamos uma valorização excessiva da denominação Pax Augusta que Estrabão dá a Pax Iulia, podendo apenas tratar-se de um erro provocado ou não pela sua elevação de estatuto num período relativamente curto após a fundação de Emerita em 25 a.C., não deixa de ser significativo o facto de as três cidades aparecerem enumeradas em conjunto. Tal sugere um mesmo processo político de elevação de estatuto colonial que se teria iniciado com a fundação da capital de província e se concluía, uma década depois, com a criação das civitates, o alargamento das deductiones militares e a constituição de novas colónias.

Depois das campanhas cântabras, do constante clima de instabilidade e insurreições de 19 a.C. submetidas por Agrippa, por novas revoltas e sublevações várias que duraram até pelo menos 16 a.C. ${ }^{23}$ Augusto viu que teria de intervir na organização do território de forma a controlá-lo, desenvolvê-lo e integrá-lo no modo de vida romano. E para o conseguir já não bastaria o estabelecimento de uma capital de província controlada por um governador, mas era necessário que essa capital provincial estendesse o seu poder e controlo de forma tentacular criando outros centros urbanos privilegiados no território.

É certamente no quadro desta estratégia integradora e de concepção de poder regional mais distribuído pelo território, com o claro objetivo de melhor o controlar, que alguns oppida serão escolhidos como lugares centrais de civitates cujos limites procurarão respeitar fronteiras, naturais ou culturais pré estabelecidas, a fim de que esta reforma se faça da maneira mais pacífica possível. A lista de Plínio, como reflexo da representação gráfica do Império do mapa de Agrippa, tem sido vista como um indicador dos oppida escolhidos como lugares centrais das civitates, uma vez que a rede urbana desenhada apontava, antes de mais, para o quadro político administrativo e fiscal do Império destinado a servir funcionários e governantes, quer imperiais quer provinciais, e militares. Na província da Lusitânia do total de 45 cidades 36 eram estipendiárias (Plínio, IV 117). A avaliar por aquela lista, na parte sul da Lusitânia

22 Alfoldy, 2000.

23 Le Roux 2006, 94. 
(consideramos apenas o território abaixo do paralelo de Olisipo /Salacia/ Ebora / Emerita Augusta) para além da colónia de Pax Iulia e do oppidum de direito latino antigo de Mirtilis, teríamos como oppida stipendiaria, Mirobriga, Arandis, Cilpes, Ossonoba e Balsa. Claro que haveria outros oppida e muito se tem discutido se não seria Laccobriga a capital da civitas mais oriental do Algarve em vez de Cilpes. Baesuris, junto à foz do Guadiana e Ipses (talvez ainda Mainoba do papiro de Artemidoro) seriam outros oppida do Algarve relativamente importantes mas que não teriam sido escolhidos como cabeças de civitates.

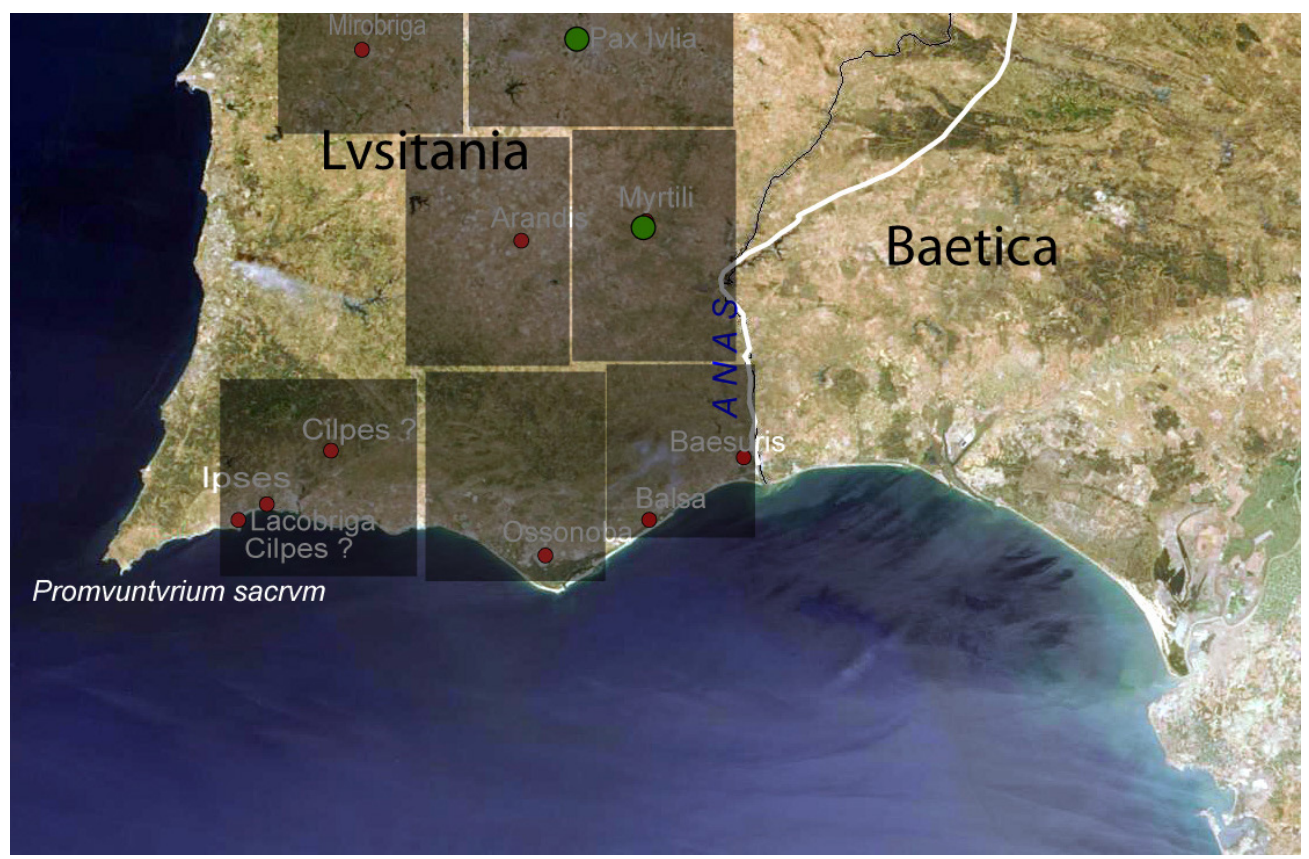

Fig. 2. A constituição das civitates do sul da Lusitânia entre 15 -13 a.C.

A definição das civitates e a escolha das suas capitais, mesmo procurando respeitar as entidades sociais e territoriais preexistentes, não deixa de se fazer de acordo com uma estratégia bem definida e que serve os interesses de Roma. Desde logo os povoados alcandorados no cimo dos montes em posições estratégicas como seriam o caso de Baesuris, ou Cerro do Cavaco, ainda que importantes durante a implantação de Roma, são frequentemente excluídos da escolha das capitalidades a favor de outras topografias, mais próximas dos recursos e das vias de comunicação e que melhor se adaptam ao novo modo de vida; depois mesmo que determinado lugar central tenha sido eleito como capital de civitas necessita de elites que promovam os melhoramentos necessários exigidos pelo novo estatuto e com isso atraia novas gentes e dinâmicas. É certo que nos critérios de escolha terá sido em conta a presença de elites indígenas, que constituíam o grosso dos efetivos da ordem administrativa romana e que garantiam no terreno a implantação e o desenvolvimento do novo con- 
ceito de centro e de território. Mas essas elites poderão também elas ser atraídas por outros centros regionais mais pujantes que acabam por absorver de factum ou de iure povoados centrais vizinhos. Veja-se a este propósito o que terá acontecido aos povoados de Castra Sevilia e Castra Caecilia que, segundo Plínio (IV 117) são cidades contributa de Norba Caesarina. O estatuto de colónia desta última e o consequente desenvolvimento que atingiu acabou por ofuscar e integrar administrativamente nos finais do século I a.C. os povoados vizinhos que décadas antes tinham desempenhado papel importante na região.

O mesmo poderá ter acontecido com a escolha da sede dos cilibitani para capital da civitas do Algarve ocidental. Talvez devido à falta de elites que permaneçam no local, à falta de investimentos e ao seu posicionamento mais periférico que levam às principais vias a não se estenderem até ali, sejam as razões conjugadas para a capital de civitas não ter tido sucesso. Até ao momento, não se conhecem quaisquer testemunhos epigráficos ou elementos de arquitectura monumental que configure uma cidade de modelo itálico e período imperial, semelhante ao que se passa com o Algarve Oriental. A cidade ao não conseguir afirmar o seu desenvolvimento foi incapaz de manter a sua autonomia fiscal e administrativa e a partir do século I e os seus territórios poderão ter sido contributa de Ossonoba. Tal justifica porque razão o itinerário de Antonino, que é antes de mais um itinerário que replica itinerários fiscais, omite qualquer estação a ocidente de Ossonoba, dirigindo-se a partir desta cidade para norte a caminho de Arandis. O iter excluía assim o Algarve Ocidental uma vez que ali não haveria qualquer centro fiscal, ou centro urbano importante que concentrasse negócios geradores de impostos, ainda que a região tivesse atividades económicas espalhadas pelo território comprovado pela existência de villae e outros sítios rurais e marítimos. Desta forma e apesar de se terem definido três civitates para o Algarve, ao longo dos séculos I e II d.C. o extremo sul de Portugal apresenta apenas duas cidades/ urbes de modelo itálico e que parecem controlar toda a região em período imperial, assumindo Ossonoba, neste quadro, um lugar cimeiro. Um marco miliário encontrado na via Balsa-Ossonoba e datando do tempo de Augusto ou pouco depois (IRCP 660) sugere que grandes obras públicas daquelas cidades com vista a dotá-las de infra-estruturas necessárias ao seu novo estatuto de capitais político-administrativas se iniciaram por aquela altura. E se esta via foi decisiva para dinamizar as actividades económicas das duas cidades lusitanas, conforme testemunham os vestígios arqueológicos, também será determinante para a ocupação e desenvolvimento de todo o território. Com efeito, é a partir de Augusto que se torna clara uma exploração efectiva das terras através de villae que começam a proliferar por todo o território ainda na primeira metade do século I. Esse dinamismo é testemunhado pela evidência arqueológica rural e urbana da região do Algarve que levará, de facto, à afirmação da capitalidade e monumentalização dos dois grandes centros regionais de Ossonoba e Balsa.

Se no Algarve, de acordo com a lista pliniana, foram definidas três civitates que dividiam o extremo sul da Lusitânia entre si, temos a norte daquela região portuguesa a definição de mais duas circunscrições administrativas: Mirtilis e Aranni ou Arandis.

Já escrevemos noutro lugar que apesar de Arandis, que localizámos em Santa Bárbara dos Padrões, ter sido escolhida como capital de civitas a oriente de Mirtilis, 
nunca teria atingido um grau de desenvolvimento tal que lhe permitisse assumir as características de uma cidade monumental de tipo itálico; ${ }^{24}$ seria nesse sentido uma cidade falhada porque não conseguiu constituir-se como um verdadeiro foco de desenvolvimento regional, uma vez que não conseguiu contrariar a forte atractividade dos centros urbanos vizinhos de Mirtilis ou Pax Iulia. Mas este é um caso diferente de Cilpes. Aceitando que a área arqueológica de Santa Bárbara corresponde aos vestígios da capital da civitas dos aranditani, teríamos aqui uma ocupação até à Antiguidade tardia, ainda que sem nunca atingir características de monumentalidade. É que se Cilpes, mesmo sendo escolhida como cidade capital, acaba por desaparecer em pleno período imperial, tal como Baesuris, Laccobriga e muitos outros povoados face à avalanche de inovações administrativas iniciadas com Augusto, no caso de Arandis o seu insucesso nunca se consumará num total abandono. Tal seria justificado por constituir uma estação viária a meio caminho entre Ossonoba, um dos portos mais importantes do sul da Lusitânia, e a capital do respectivo conventus: a colónia Pax Iulia. Na verdade, como recentemente defendeu Julio Mangas nem todos os centros fiscais ou administrativos teriam que ter burgo monumental, e, sobretudo nas zonas mais recônditas da Hispânia, as unidades de gestão e controlo fiscal ou administrativo dos territórios poderia assumir múltiplas configurações, ao ponto até de não terem urbs. ${ }^{25}$ Mas em zonas bem romanizadas como acontecia com o extremo sul da Lusitânia, a gestão dos territoria, de acordo com a concepção que Augusto desenvolveu do Império, fazia-se a partir das cidades e com as suas elites.

À latitude de Mirtilis e Arandis, haveria espaço para uma terceira civitas na área mais ocidental. Este território, correspondente ao actual concelho de Odemira, sempre foi pouco povoado, pelo que poderia não se justificar aqui a definição de uma civitas. Ainda que o ordenamento político administrativo, enquanto mecanismo pensado para controlar e integrar todo o território, procurasse que as circunscrições administrativas se distribuíssem de forma equilibrada por toda a província, era natural haver um maior número de civitates em áreas territoriais com mais densidade populacional. Em muitos casos, concretamente em regiões onde a população era escassa, poderia mesmo não se definir qualquer civitas, ficando o território sob a alçada de uma cidade vizinha, ou simplesmente como terra de ninguém. Destas res nulius, que num primeiro momento não integravam civitates, poderiam vir a constituir-se posteriormente novas circunscrições administrativas, caso se justificasse, ou então parte dessas terras passariam a integrar territórios de civitates já existentes. Aceitando que a criação das civitates no sul da Lusitânia se enquadra no movimento de reestruturação e reordenamento administrativo de toda a Hispânia ocorrido entre 15 a.C. e 13 a.C., talvez que a delimitação de várias civitates levada a cabo pelo governador provincial Quintus Articuleius Regulus a norte do rio Tejo, entre 4 e 6 d.C. ${ }^{26}$ corresponda a uma dessas redifinições posteriores das fronteiras das civitates. Os oito termini augustales que atestam essas delimitações devem ser vistos como parte do mesmo processo de definição das civitates que não se iniciou e acabou num único momento mas, como

24 BERNARDES 2006.

25 Mangas 2014.

26 Cortés Barcena 2002-03, 115, 121-122; Alarcão 2005, 269. 
é habitual na definição de limites territoriais, foi sendo definido e ajustado. Ainda assim, era natural que as fronteiras entre territórios permanecessem mais ou menos difusas. A colocação dos termini procurava, sobretudo em etnogeografias mais sensíveis, clarificá-las, evitando possíveis conflitos, mas houve sempre zonas onde o limes dos territórios ficou por definir com precisão. Será essa indefinição que levou, nos inícios do século III, um proprietário residente no limite do território de Conimbriga com o de Sellium a tornar explícito através de uma inscrição, certamente dirigida aos cobradores de impostos, que pagava as suas rendas ao município vizinho: VE[ctigale] R[ei] P[ublicae] M[unicipii] VICINI. ${ }^{27}$ Este caso parece elucidar que mesmo as divisões entre civitates do centro da Lusitânia, plenamente inseridas na nova ordem administrativa romana, continuaram durante séculos a levantar dúvidas ao ponto de haver necessidade de tornar público a quem era devido e pago o vectigale, certamente pelo uso de terras públicas.

Os territórios a norte de Mirtilis e de Arandis dividiam-se pela civitas pacensis e pela dos Mirobrigenses. Ambas as cidades estão identificadas, ainda que pouco se conhece sobre a real importância de Pax Iulia que deveria ser muita. Colónia e sede de conventus, dominava todo o sul da Lusitânia e, juntamente com Ebora, funcionaria como uma verdadeira extensão da capital emeritense em toda a região a sul do Tejo. Miróbriga e Pax Iulia, oppida pré-romanos, eram pólos de atractividade para onde se deslocam populações de antigos povoados que acabaram, paulatinamente, abandonados, como vimos para a parte mais meridional da Lusitânia. Miróbriga nunca deixará de constituir uma pequena cidade ao passo que a colónia pacensis terá um papel determinante no desenvolvimento do sul da Lusitânia, funcionando como um esteio na estratégia político - administrativa definida para a região em que Emerita Augusta é o centro e Pax Iulia uma sua extensão. A influência de Pax Iulia irá retirar algum protagonismo regional às capitais de civitates mais próximas, nomeadamente a Arandis e, de certa forma, até a Mirtilis. As civitates no sul da Lusitânia terão percursos evolutivos muito assimétricos. Quer porque não havia recursos e populações suficientes para o desenvolvimento significativo de todas, quer ainda pela hierarquia administrativa e posicionamento geográfico que detinham, umas acabarão por captar a maior parte dos recursos, eclipsando o desenvolvimento de outras.

\section{A Evolução do legado de Augusto no sul da Lusitânia}

Convergindo os elementos políticos e os aspectos administrativos, a acção de Augusto leva a uma alteração total na forma de organização territorial e social das comunidades. Nessa acção destaca-se o uso inteligente e controlado de ferramentas administrativas e jurídicas, de que o édito de Bierzo, com as alterações das relações entre povos antes instituídas, ou a constituição das civitates, com o reagrupamento de populações, constituem exemplos paradigmáticos. Estes mecanismos acabarão por subverter paulatinamente as estruturas sociais pré-romanas, até ao seu desmantela-

27 MonTEIRo - ENCARNAÇÃo 1993-1994, 303-311. 
mento, proporcionando a formação de novas redes e criando uma nova ordem de acordo com modelos itálicos e interesses de Roma.

Com a reorganização político-administrativa e a definição ou reafirmação de centralidades e eixos de circulação decorrentes de uma nova lógica da hirerarquização e estruturação do território, é natural que espaços antigos percam a sua primazia e influência a favor de núcleos até aí secundarizados ou mesmo inexistentes. Nem todos os territoria inicialmente definidos terão sucesso o que, a prazo, levará à completa diluição da estrutura tribal do sul da Lusitânia a favor do modelo urbano que controla o território. Neste aspecto é paradigmático a quase ausência de divindades e antropónimos de origem indígena na epigrafia do sul da Lusitânia em claro contraste com o centro ou norte da mesma província. ${ }^{28}$

Como consequência do novo ordenamento vai assistir-se nas décadas seguintes a rearranjos profundos da rede de lugares centrais. A fundação da capital da Lusitânia em 25 a.C., para além de ter afectado desde o início algumas comunidades vizinhas, como Lacimurga, à medida que se foi desenvolvendo e ganhando cada vez mais o estatuto de uma pequena Roma do Ocidente, sobretudo a partir do período dos Flávios, acabará inevitavelmente por asfixiar as colónias próximas de Metellinum e de Norba Caesarina. ${ }^{29}$ Os núcleos com uma longa e velha tradição de ocupação indígena vão cedendo cada vez mais espaço à cidade romana de modelo itálico e à nova rede político-administrativa desenhada por Augusto. Também na Tarraconense, a fundação da colónia de Caesaraugusta cedo eclipsará Celsa, uma criação de Lépido. ${ }^{30}$

Mesmo nas regiões mais afastadas dos grandes centros provinciais o fenómeno também ocorre. Já vimos o caso de efeito quase imediato que a reforma augustana terá tido em Mesas dos Castelinhos, na área de Arandis, onde se situam os actuais concelhos de Castro Verde, Ourique e Almodôvar. Toda esta região do Baixo Alentejo, com uma forte presença e tradição de ocupação na Idade do Ferro, como é, de resto, comprovado por vários santuários, povoados importantes e ainda por uma tipologia própria de estelas, ${ }^{31}$ perde importância a partir de Augusto em virtude de emergirem grandes núcleos político-administrativos com a criação das civitates. O próprio núcleo de Arandis devido à forte vocação centralizadora de Mértola e de Beja, acabará por nunca atingir um desenvolvimento assinalável e mesmo Mirtilis, a partir de meados do século I d.C. parece perder parte do brilhantismo do século anterior, provavelmente a favor dos protagonismos de Pax Iulia e de Emerita Augusta. Já no extremo sul da Lusitânia vários oppida e territoria vão perdendo influência ao ponto de se diluírem noutros centros de sucesso até desaparecerem. Baesuris alimentará o desenvolvimento de Balsa e, na parte ocidental do Algarve, cidades pré-romanas como Cilpes, Laccobriga ou Ipses começam a definhar, sendo as suas elites atraídas pelas novas capitalidades, como Ossonoba, ou instaladas nas villae e outros focos económicos do seu território. Aqueles antigos centros acabam abandonados por volta do século II, ao passo que as duas cidades marítimas de Balsa e Ossonoba prospera-

\footnotetext{
28 ENCARNAÇÃO 1984.

29 EDMONSON 2011, 46.

30 Le Roux 2006, 120.

31 Le Roux 2006, 813.
} 
vam e aproveitavam do dinamismo da rota atlântica que a pacificação dos mares e a conquista da Britania por Cláudio proporcionavam. Nos territoria controlado pelas duas cidades prosperavam ainda novas povoações dedicadas às actividades marítimas e que articuladas com os centros urbanos e as rotas comerciais correspondem perfeitamente, a par da villae nos meios rurais, a modelos de exploração económica do tipo itálico.

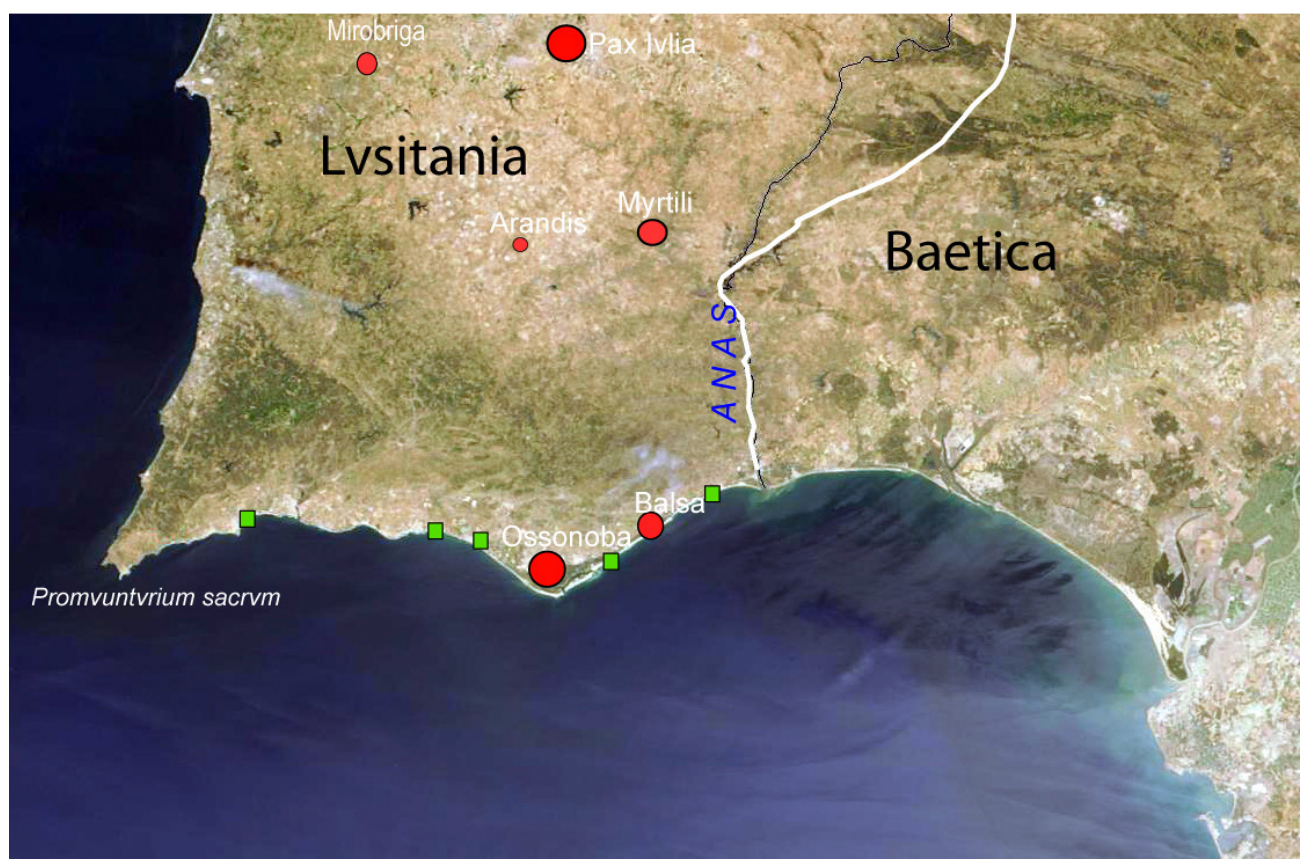

Fig. 3. A nova paisagem politico-administrativa após o desmantelamento das estruturas e redes pré-romanas.

A reforma administrativa de Augusto que mais assume laivos de uma verdadeira Revolução, acaba por criar uma nova Hispânia. A prazo, as estruturas indígenas e as redes de tipo tribal, que no tempo de octaviano ainda persistiam no sul da Lusitânia, tendem a desaparecer. $\mathrm{O}$ desmantelamento dessas estruturas antigas, enquanto parte do plano de Augusto para a integração das províncias, constituiu o culminar de toda a sua reforma, que começou com a grande originalidade de criar novas centralidades em povoados indígenas ou de raíz integrados numa rede hierarquizada. Um século após a sua reforma, a nova Hispania, muito diferente da que saiu da fase das conquistas, está consolidada como uma província verdadeiramente romana nascida do seu génio político e visionário. $\mathrm{O}$ grande objectivo da reforma administrativa de Augusto estava cumprido! 


\section{BiBLIOGRÁFIA}

AlARCÃo, J.

(1990): "Identificação das cidades da Lusitânia portuguesa e dos seus territórios", [in] Les villes de Lusitanie romaine: Hiérarchies et territoires. Table ronde internationale du CNRS, Talence, le 8-9 décembre 1988 (Collection de la Maison des Pays Ibériques, 42), Paris, 21-34.

(2005): "Notas de arqueologia, epigrafia e toponímia - III", Revista Portuguesa de Arqueologia 8/2, Lisboa, 293-311.

(2010): “A Costa Portuguesa em Artemidoro", Revista Portuguesa de Arqueologia 13, 107-123.

AlföLdy, G. (2000): “Das neue Edikt des Augustus aus El Bierzo in Hispanien”, Zeitschrift für Papyrologie und Epigraphik 131, 177-205.

Arruda, A. M. (2002): Los Fenicios en Portugal. Fenícios y mundo indígena en el centro y sul de Portugal (siglos VIII-VI a.C.) Barcelona (= Cuadernos de Arqueología Mediterránea, vol 5-6, 1999-2000).

Arruda, A. M. ET AL. (2008): "Monte Molião (Lagos): resultados de um projecto em curso", Xelb 8 (=Actas do $5^{\circ}$ Encontro de Arqueologia do Algarve Vol I., Silves) 137-168.

Bernardes, J. P. (2006): “A Propósito da Localização de Aranni/ Arandis”, Conimbriga, 45, 153-164.

BernARDES, J. P. (2010): “Ab Oppido ad Urbem: Algarve's urban landscape variations throughout the Roman age", [in] C. Corsi - F. Vermeulen (eds.), Changing Landscapes. The impact of Roman towns in the Western Mediterranean, Bologna, 357-368.

Cortés BARCENA, C. (2002-2003): "Epigrafia y Territorio en la Hispania Romana: Los Termini Públicos", Anas 15/16, 107-126.

$C I L=$ Corpus Inscriptionum Latinarum, Berlin.

DCPH II = Garcia-Bellido - García de Diego, M. P. - Blázquez Cerrato, C. (2001) [2002]: Diccionario de cecas y pueblos hispánicos. Con una introducción a la numismática antigua de la Península Ibérica. Volumen II: catálogo de cecas y pueblos que acuñan moneda. Madrid.

Edmonson, J. (2011): “A Tale of Two Colonies: Augusta Emerita (Merida) and Metellinum (Medellin) in Roman Lusitania", [in] R. J. Sweetman (ed.), Roman Colonies in the First Century of their Foundation, Oxford, 32-54.

EnCARnação, J. (1984): Inscrições romanas do Conventus Pacensis, Universidade de Coimbra.

FABĩ̃o, C. - Guerra, A. (2010): "Mesas de Castelinho (Almodôvar): A case of failed Roman town in southern Lusitania", [in] C. Corsi - F. Vermeulen (eds.), Changing Landscapes. The impact of Roman towns in the Western Mediterranean, Bologna, 325-346.

FARIA, A. M.

(1995): "Plínio-o-Velho e os estatutos das cidades privilegiadas hispano-romanas localizadas no actual território português", Vipasca 4, 89-99.

(1997): "Moedas da época romana cunhadas no actual território algarvio", [in] Noventa séculos entre a serra e o mar, Lisboa, 361-371.

(2006): "Novas notas historiográficas sobre Augusta Emerita e outras cidades hispano-romanas", Revista Portuguesa de Arqueologia 9/2, 211-237. 
Gallazzi, C. - Kramer, B. - Settis, S. (2008): Il papiro di Artemidoro (con la collaborazione di G. Adornato, A. C. Cassio y A. Soldati,) Milano.

García-Bellido, Ma P. - Blázquez, C. (2001): Diccionario de cecas y pueblos hispánicos. Con una introducción a la numismática antigua de la Península Ibérica. Volumen II: catálogo de cecas y pueblos que acuñan moneda (Colección Textos Universitarios, 36), Madrid.

Guerra, A. (1995): Plínio-o-Velho e a Lusitânia, Lisboa.

IRCP = ENCARNAÇÃo, J. (1984): Inscrições romanas do Conventus Pacensis, Coimbra.

Lopes, M. C. (2003): A cidade romana de Beja. Percursos e debates acerca da "civitas" de Pax Ivlia, Coimbra.

KEAY, S. (2003): "Recent archaeological work in Roman Iberia (1990-2002)", The Journal of Roman Studies 93, 146-211.

Kramer, B. (2006): “La Península Ibérica en la Geografía de Artemidoro de Éfeso", [in] G. Cruz Andreotti et al. (eds.), La invención de una geografía de la Península Ibérica, I. La época republicana (Actas del Coloquio Internacional celebrado en la Casa de Velázquez de Madrid entre el 3 y el 4 de marzo de 2005), Málaga-Madrid, 97-114.

Le Roux, P. (2006): Romanos de España. Ciudades y Politica en las Provincias (Siglo II a.C. - Siglo III d.C.), Barcelona.

Mangas, J. (2014): “Ciudades sin urbe en la Hispania”, [in] A. Martínez Fernández (ed.), Ágalma, Ofrenda desde la Filología Clásica a Manuel García Teijeiro, Valladolid, 807830.

Mantas, V. G.

(1993): "As fundações coloniais no território português nos finais da República e inícios do Império", [in] Actas do II Congresso Peninsular de História Antiga (Coimbra, 18 a 20 de Outubro de 1990), Coimbra, 467-500.

(1997): "As civitates: Esboço da geografia política e económica do Algarve romano", [in] Noventa séculos entre aserra e o mar, Lisboa, 283-309.

Monteiro, A. J. N. - EnCARnaÇÃo, J. (1993-1994): “A propósito de uma inscrição latina em Santiago da Guarda (Ansião)”, Conimbriga 32-33, 303-311.

Nicolet, C. (1991): Space, Geography, and Politics in the Early Roman Empire, Ann Arbor (MI).

QuARESMA, J. C. (2012): Economia antiga a partir de um centro de consumo lusitano: terra sigillata e cerâmica africana de cozinha em Chãos de Salgados (Mirobriga?), Lisboa.

Ruiz Acevedo, J. M. - CAmpos CARrasco, J. M. (2009): "El litoral onubense y algarveño en el Papiro de Artemidoro: una nueva interpretación", Habis 40, 89-107.

Sánchez-Palencia F. J. - Mangas J. (coords.) (2000): El Edicto de El Bierzo. Augusto y el Noroeste de Hispania, Ponferrada.

Spann, O. PH. (1981): "Lagobriga Expunged: Renaissance Forgeries and the Sertorian War", Transactions of the American Philological Association 111, 229-235.

Torres, C. - Lopes, V. (2012): Casa Romana: Museu de Mértola, Mértola.

Wallace-Hadrill, A. (2008): Rome's Cultural Revolution, Cambridge. 